Care: Jurnal Ilmiah Ilmu Kesehatan Vol .6, No.3,2018,hal 200-209

Tersedia online di https://jurnal.unitri.ac.id/index.php/care

ISSN 2527-8487 (online)

ISSN 2089-4503 (cetak)

\title{
Analisa Deteksi Dini dan Stimulasi \\ Perkembangan Anak Usia Prasekolah
}

\author{
Miftakhul Ulfa \\ Stikes Widyagama Husada Malang \\ e-mail: mimiulfah@yahoo.com
}

\begin{abstract}
$A B S T R A C T$
The Early Detection and Development Stimulation Program is one of the health examination programs that aims to find developmental irregularities in children under five and preschoolers early, comprehensive and coordinated in the form of partnerships between families (parents, caregivers and other family members), the community (cadres, professional organizations) with professionals. Monitoring of child development includes monitoring from physical, psychological and social aspects. The aim of the study was to analyze the development of kindergarten and knowledge students (parents and kindergarten teacher Aisyiyah Bustanul Athfal 12) in early detection and developmental stimulation in preschool children. The research method used is quantitative with analytical survey methods with 35 respondents. The results of the study showed that there were a number of students experiencing deviations in the KPSP examination of 4 students, 5 students experiencing attention deficit disorder and hyperactivity and 1 student who experienced autism and $100 \%$ of respondents (parents and teachers) responded positively in terms of very bigh efficacy for early detection of child developmental disorders.
\end{abstract}

Keywords: early detection; development; preschool children

\begin{abstract}
ABSTRAK
Program deteksi dini dan stimulasi perkembangan merupakan salah satu program pemeriksaan kesehatan yang bertujuan untuk menemukan penyimpangan perkembangan pada balita maupun anak usia prasekolah secara dini, menyeluruh dan terkoordinasi diselenggarakan dalam bentuk kemitraan antara keluarga (orang tua, pengasuh anak dan anggota keluarga lainnya), masyarakat (kader, organisasi profesi) dengan tenaga professional. Pemantauan perkembangan anak meliputi pemantauan dari aspek fisik, psikologi, dan sosial. Tujuan penelitian untuk menganalisa perkembangan siswa TK dan pengetahuan (orang tua dan guru TK Aisyiyah Bustanul Athfal 12) dalam deteksi dini dan stimulasi perkembangan pada anak prasekolah. Metode penelitian yang digunakan kuantitatif dengan metode survei analitik 35 responden. Instrument yang digunakan KPSP, deteksi autis (CHAT), deteksi gangguan emosional (KMEE) dan deteksi gangguan pemusatan perhatian dan hiperaktivitas (GPPH).Hasil penelitian, didapatkan bahwa ada beberapa siswa mengalami penyimpangan pada pemeriksaan KPSP sejumlah 4 siswa, sejumlah 5 siswa mengalami gangguan pemusatan perhatian dan hiperaktivitas, 1 siswa mengalami autis dan $100 \%$ responden (orang tua dan guru ) merespon positif dalam hal kemanfatan yang sangat tinggi untuk melakukan deteksi dini kelainan perkembangan anak.
\end{abstract}

Kata kunci : anak prasekolah; deteksi dini; perkembangan 


\section{PENDAHULUAN}

Program Deteksi Dini dan Stimulasi

Perkembangan merupakan salah satu program pemeriksaan kesehatan yang bertujuan untuk menemukan penyimpangan perkembangan pada balita maupun anak usia prasekolah secara dini, menyeluruh dan terkoordinasi diselenggarakan dalam bentuk kemitraan antara keluarga (orang tua, pengasuh anak dan anggota keluarga lainnya), masyarakat (kader, organisasi profesi, lembaga swadaya masyarakat) dengan tenaga professional (Depkes, 2007). Pemantauan perkembangan anak meliputi pemantauan dari aspek fisik, psikologi, dan sosial. Pemantauan tersebut harus dilakukan secara teratur dan berkesinambungan.

Pemantauan tumbuh kembang anak usia prasekolah merupakan fase yang penting, karena dapat menentukan kualitas kesehatan, kesejahteraan, pembelajaran dan perilaku di masa mendatang (IDAI, 2016). Penelitian Putri,dkk (2016) di TK Pesantren Al Madaniyah ditemukan bahwa sebagain besar anak pra sekolah mempunyai pertumbuhan yang baik, dilihat dari berat dan tinggi badan yang berimbang. Bertentangan dengan Hasil Riset IDAI (2016) menunjukkan bahwa sekitar 1-3\% anak dibawah usia 5 tahun mengalami keterlambatan tumbuh kembang. Dengan ditemukan secara dini penyimpangan atau permasalahan perkembangan anak, maka intervensi akan lebih mudah dilakukan, baik oleh tenaga kesehatan, orang tua maupun guru di sekolah. Bila penyimpangan terlambat diketahui, maka intervensinya akan lebih sulit dan hal ini akan berpengaruh pada perkembangan anak (Depkes, 2007).

Program penelitian yang diselenggarakan oleh Stikes Widyagama Husada bekerjasama dengan mitra Sekolah TK Aisyiyah Bustanul Athfal 12 Malang. Mitra merupakan guru dan orang tua siswa TK Aisyiyah 12 yang berperan aktif dan bertanggung jawab dalam mewujudkan generasi bangsa yang sehat. Peran orang tua dan Guru di Sekolah sangat penting untuk melakukan pemantauan perkembangan pada anak, sehingga diperlukan pengetahuan dan keterampilan yang baik tentang kesehatan anak, salah satunya pengetahuan tentang pemeriksaan dan cara detekesi dini masalah perkembangan pada anak.

Berdasarkan hasil wawancara dengan Kepala Sekolah TK Aisyiyah Bustanul Athfal 12 Malang memaparkan bahwa pelaksanaan deteksi dini perkembangan yang sudah dilakukan oleh guru terhadap semua siswa TK A, B dan Kelompok 
Bermain hanya terbatas pada pemeriksaan pertumbuhan saja yaitu pengukuran berat badan, tinggi badan dan lingkar kepala. Selain itu juga para guru maupun orang tua wali siswa belum pernah mendapatkan edukasi, penyuluhan maupun pelatihan terkait deteksi dini dan stimulasi perkembangan pada anak usia prasekolah secara komprehensif.

Berdasarkan permasalahan tersebut peneliti tertarik untuk menganalisis deteksi dini dan stimulasi perkembangan anak usia prasekolah. untuk mengetahui adanya penyimpangan perkembangan anak sedini mungkin sehingga dapat dilakukan upaya penanganan segera guna mewujudkan generasi bangsa yang sehat dengan pertumbuhan yang optimal

\section{METODE PENELITIAN}

Jenis penelitian yang digunakan adalah penelitian kuantitatif dengan metode survey analitik (Notoatmojo, 2012). Pengambilan data dalam kegiatan penelitian yang dilakukan di sekolah TK Aisyiyah Bustanul Athfal 12 Malang dibedakan menjadi dua kegiatan yaitu: 1). Screening deteksi dini perkembangan yang dilakukan pada 35 siswa (TK A, B dan Kelompok Bermain). Kegiatan ini, diharapkan dapat mendeteksi kemampuan perkembangan anak sesuai dengan usia.
Pemantauan perkembangan anak dilakukan dengan instrument KPSP, deteksi autis (CHAT), deteksi gangguan emosional (KMEE) dan deteksi gangguan pemusatan perhatian dan hiperaktivitas (GPPH), 2). Kegiatan Psikoedukasi berupa Seminar Sehari dengan tema“ Deteksi Dini dan Stimulasi Perkembangan pada Anak Usia Prasekolah". Kegiatan ini dilaksanakan dengan sasaran semua orang tua siswa dan Guru TK A, B dan Kelompok Bermain (77 responden). Kegiatan ini, diharapkan orang tua wali murid dan guru dapat memahami pentingnya deteksi dini dan stimulasi perkembangan pada anak

\section{HASIL}

Berdasarkan Karakteristik Siswa TK menurut usia, tinggi badan dan berat badan pada Tabel 1 didapatkan bahwa mayoritas usia siswa di Sekolah TK Aisyiyah Bustanul Athfal 12 Malang adalah berusia 5 tahun sejumlah 19 orang (54,3\%), karakteristik responden berdasarkan tinggi badan didapatkan bahwa mayoritas siswa di Sekolah TK Aisyiyah Bustanul Athfal 12 Malang mempunyai tinggi badan sekitar $101-111 \mathrm{~cm}$ sejumlah 23 orang (65,7\%). Dan karakteristik siswa berdasarkan berat badan didapatkan bahwa mayoritas Siswa di Sekolah TK Aisyiyah Bustanul Athfal 
12 Malang mempunyai berat badan sekitar

10-15 kg sejumlah 18 orang (51,4\%).

Tabel 1. Karakteristik Siswa TK A, B, dan Kelompok Bermain di Sekolah TK Aisyiyah Bustanul Athfal 12 Malang

\begin{tabular}{lcc}
\hline Usia & Jumlah & $\%$ \\
\hline 3 tahun & 1 & 2,9 \\
4 tahun & 8 & 22,9 \\
5 tahun & 19 & 54,3 \\
6 tahun & 7 & 20 \\
\hline Total & 35 & 100 \\
\hline Berat Badan $(\mathrm{kg})$ & & \\
\hline $10-15 \mathrm{~kg}$ & 18 & 51,4 \\
$16-21 \mathrm{~kg}$ & 16 & 45,7 \\
$22-27 \mathrm{~kg}$ & 1 & 2,9 \\
\hline Total & 35 & 100 \\
\hline TinggiBadan & & \\
(cm) & & \\
\hline $90-100$ & 12 & 34,3 \\
$101-111$ & 23 & 65,7 \\
\hline Total & 35 & 100 \\
\hline
\end{tabular}

Sumber data : Data Primer (2018)

Tabel 2. Hasil Pemeriksaan KPSP pada Siswa TK A, B dan Kelompok Bermain di Sekolah TK Aisyiyah Bustanul Athfal 12 Malang

\begin{tabular}{lcc}
\hline KPSP & Jumlah & $\mathbf{\%}$ \\
\hline Sesuai & 31 & 88,6 \\
Penyimpangan & 4 & 11,4 \\
\hline Total & 35 & 100 \\
\hline Sumber Data: Data Primer (2018)
\end{tabular}

Tabel 2 menunjukkan bahwa mayoritas siswa di Sekolah TK Aisyiyah Bustanul Athfal 12 Malang mempunyai tumbuh kembang yang sesuai dengan usianya yaitu 31 orang $(88,6 \%)$.

Berdasarkan Hasil Pemeriksaan KMEE pada Tabel 3 didapatkan bahwa mayoritas siswa di Sekolah TK Aisyiyah Bustanul Athfal 12 Malang pada deteksi gangguan emosional dalam tahap normal yaitu 16 orang $(45,7 \%)$.

Tabel 3. Hasil Pemeriksaan KMEE pada Siswa TK A, B, Kelompok Bermain di Sekolah TK Aisiyah Bustanul Athfal 12 Malang

\begin{tabular}{|c|c|c|}
\hline $\begin{array}{l}\text { Pemeriksaan } \\
\text { KMEE }\end{array}$ & Jumlah & $\%$ \\
\hline Normal & 16 & 45,7 \\
\hline $\begin{array}{l}\text { Rujuk } \\
\text { Pelayanan } \\
\text { Tumbuh } \\
\text { Kembang }\end{array}$ & 11 & 31,4 \\
\hline $\begin{array}{l}\text { Evaluasi } \\
\text { setelah } 3 \text { bulan }\end{array}$ & 8 & 22,9 \\
\hline Total & 35 & 100 \\
\hline
\end{tabular}

Tabel 4. Hasil Pemeriksaan AUTIS pada Siswa TK A, B, Kelompok Bermain di Sekolah TK Aisiyah Bustanul Athfal 12 Malang

\begin{tabular}{lcc}
\hline $\begin{array}{l}\text { Pemeriksaan } \\
\text { Autis }\end{array}$ & Jumlah & $\%$ \\
\hline Normal & 34 & 97,1 \\
Autis & 1 & 2,9 \\
Total & 35 & 100 \\
\hline
\end{tabular}

Sumber Data : Data Primer (2018)

Berdasarkan Hasil Pemeriksaan Autis pada pada Tabel 4 didapatkan bahwa mayoritas siswa di Sekolah TK Aisyiyah Bustanul Athfal 12 Malang pada deteksi autis dalam tahap normal yaitu 34 $\operatorname{orang}(97,1 \%)$. 
Berdasarkan Hasil Pemeriksaan GPPH pada Tabel 5 didapatkan bahwa mayoritas siswa di Sekolah TK Aisyiyah Bustanul Athfal 12 Malang pada deteksi GPPH dalam tahap normal yaitu 30 orang $(85,7 \%)$.

Tabel 5. Hasil Pemeriksaan GPPH pada Siswa TK A, B, Kelompok Bermain di Sekolah TK Aisiyah Bustanul Athfal 12 Malang

\begin{tabular}{lcc}
\hline GPPH & Jumlah & $\%$ \\
\hline Normal & 30 & 85,7 \\
GPPH & 5 & 14,3 \\
\hline Total & 35 & 100 \\
\hline
\end{tabular}

Sumber Data : Data Primer (2018)

\section{PEMBAHASAN}

\section{Pemeriksaan Deteksi Dini Tumbuh}

\section{Kembang}

Kegiatan penelitian yang diadakan di Sekolah TK Bustanul Athfal 12 ini mendapat respon positif baik dari orang tua wali siswa maupun guru TK A, B dan Kelompok Bermain. Kegiatan ini berhasil memeriksa pertumbuhan dan perkembangan pada siswa TK (A, B dan Kelompok Bermain) sejumlah 35 anak usia 3-6 tahun. Pemeriksaan pertumbuhan dilakukan dengan mengukur panjang atau tinggi badan anak dan berat badan anak.

Hasil pemeriksaan deteksi dini pada siswa TK (A, B dan Kelompok Bermain) didapatkan bahwa bahwa mayoritas siswa di Sekolah TK Aisyiyah Bustanul Athfal 12 Malang mempunyai berat badan rata-rata $10-15 \mathrm{~kg}$ dengan usia 5 tahun sejumlah 10 orang. Dimana hasil pemeriksaan tersebut menurut tabel standar antropometri (Kep.Menkes Nomor.1995/Menkes/SK/XII/2011)ter masuk dalam kategori gizi baik. Demikian juga hasil pengukuran tinggi badan anak, didapatkan mayoritas siswa mempunyai kategori status gizi normal berdasarkan tinggi badan rata-rata $101-111 \mathrm{~cm}$ dengan usia 5 tahun sebanyak 12 orang.

Pertumbuhan dan perkembangan pada anak baik fisik, mental, sosial, emosional dipengaruhi oleh gizi, kesehatan dan pendidikan. Hal ini sejalan dengan penelitian oleh Bloom mengenai kecerdasan yang menunjukkan bahwa dalam kurun waktu 4 tahun pertama usia anak, perkembangan kognitifnya mencapai sekitar 50\%, kurun waktu 8 tahun mencapai 80\%, dan mencapai $100 \%$ setelah anak berusia 18 tahun(Saidah, 2003).

Adanya kecerdasan otak pada anak usia prasekolah menunjukkan bahwa untuk mencapai tingkat kepandaian secara optimal pada anak, maka stimulasi tumbuh kembang harus dilakukan sejak anak berusia 3 tahun pertama dalam kehidupannya, hal ini dikarenakan anak memiliki jumlah sel otak dua kali lebih 
banyak dari sel-sel otak pada orang dewasa

(Oberlander, J.R \& Steady, 2003).

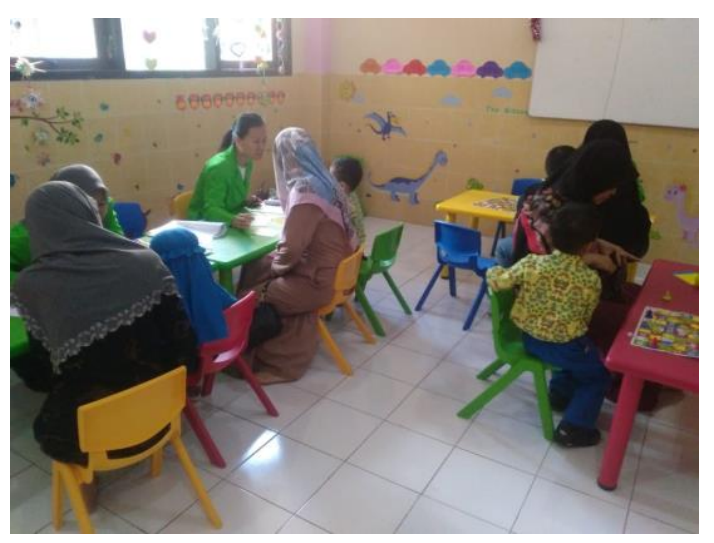

Gb.1 Pelaksanaan Screening Deteksi Dini Perkembangan pada Siswa TK)

Pemeriksaan perkembangan anak dilakukan dengan menggunakan 4 kuisioner, diantaranya kuisioner KPSP, deteksi dini gangguan emosional, deteksi dini autis dan deteksi dini hiperaktivitas(Kemenkes RI, 2012;2013).

Pemeriksaan perkembangan anak dengan instrument KPSP didapatkan sebanyak 31 orang $(88,6)$ anak perkembangannya sesuai dengan usia dan hanya $11,4 \%$ atau 4 orang dari 35 anak yang diperiksa nilai KPSP ada penyimpangan. Pada siswa dengan nilai KPSP yang menyimpang, maka orangtua diberi edukasi mengenai stimulasi perkembangan anak sesuai usia dan masalah perkembangan yang dialami oleh anak, misalkan penyimpangan pada gerak kasar, gerak halus, bicara \& bahasa, sosialisasi dan kemandirian.

Pada Hasil Pemeriksaan KMEE (Kuisioner Masalah Mental Emosional) didapatkan bahwa mayoritas siswa di Sekolah TK Aisyiyah Bustanul Athfal 12 Malang pada deteksi gangguan emosional dalam tahap normal yaitu 16 orang (45,7\%), sisanya 11 siswa perlu mendapatkan rujukan ke pelayanan kesehatan tumbuh kembang dan 8 siswa memerlukan konseling kepada orang tua melalui buku pedoman pola asuh yang mendukung perkembangan anak. Sedangkan hasil pemeriksaan deteksi dini autis, didapatkan 1 siswa mengalami autis dan 5 siswa mengalami gangguan pada pemusatan perhatian dan konsentrasi.

Selama tahap perkembangan, anak dapat mengalami berbagai gangguan yang terkait dengan psikiatri, misalnya kecemasan yang dapat dialami anak adalah fobia sekolah, kecemasan berpisah, fobia sosial, dan kecemasan setelah mengalami trauma. Gangguan perkembangan pervasif pada anak meliputi autisme serta gangguan perilaku dan interaksi sosial. Menurut Widyastuti (2008) autism adalah kelainan neurobiologis yang menunjukkan gangguan komunikasi, interaksi, dan perilaku. Autisme ditandai dengan 
Care: Jurnal Ilmiah Ilmu Kesehatan Vol .6, No.3,2018,hal 200-209

terhambatnya perkembangan bahasa, munculnya gerakan-gerakan aneh seperti berputar-putar, melompat-lompat, atau mengamuk tanpa sebab. Bila penyimpangan mental emosional terlambat diketahui maka intervensinya akan lebih sulit dan hal ini akan berpengaruh pada tumbuh kembang anak (Depkes, 2007). Hal tersebut sejalan dengan Riset Irmawati (2007) terkait Manajemen Pelaksana Kegiatan Stimulasi Deteksi dan Intervensi Dini Tumbuh Kembang (SDIDTK) dengan Cakupan SDIDTK Balita dan Anak Pra Sekolah di Puskesmas Kota Semarang menunjukkan bahwa sebagian besar kasus yang ditemukan adalah gangguan bicara dan bahasa 56,61\%, autisme 13,15\%, gangguan pemusatan perhatian dan hiperaktivitas $12,10 \%$ serta keterlambatan duduk atau berdiri 10,09\%. Bila penyimpangan terlambat diketahui, maka intervensinya akan lebih sulit dan hal ini akan berpengaruh pada tumbuh kembang $\operatorname{anak}($ Soetjiningsih, 1998).

Kondisi penyimpangan perkembangan yang terjadi pada anak usia prasekolah memerlukan perhatian yang cukup serius dari orang tua maupun guru di Sekolah TK. Hasil penelitian yang dilakukan oleh Soccoro A Gultiano dan Elizabeth M King pada tahun 2006 membuktikan bahwa orang tua mempunyai peranan yang penting dalam meningkatkan perkembangan psikososial anak. Anak usia 0-4 tahun yang dilakukan stimulasi selama 2 tahun akan meningkatkan perkembangan psikososialnya sebesar 611\%( Socorro \& Elizabeth, 2006).

\section{Kegiatan Psikoedukasi}

Pelaksanaan kegiatan Psikoedukasi berupa seminar sehari kepada wali murid siswa dan guru TK Aisyiyah Bustanul Athfal 12 Malang ini membawa hasil yang nyata sesuai dengan tujuan program yang dirumuskan sebelumnya. Evaluasi yang dilakukan menunjukkan bahwa para peserta yang mengikuti kegiatan seminar ini menyatakan bertambahnya pemahaman mereka mengenai karakteristik tumbuh kembang anak usia prasekolah dan bertambah pula keterampilan dalam mendeteksi secara dini disfungsi tumbuh kembang anak. Hasil penelitian tersebut sejalan dengan riset yang dilakukan oleh Ummah et al (2016) mengenai Optimasi Peran Guru Paud untuk meningkatkan tumbuh kembang anak prasekolah menunjukkan bahwa adanya peningkatan pengetahuan guru Paud dengan rerata pengetahuan guru meningkat 17,33 point. Penelitian yang sama juga dilakukan oleh Yuliani (2018) terhadap 10 orang guru dan 8 wali 
murid Paud dalam pelatihan stimulasi deteksi intervensi dini tumbuh kembang (SDIDTK) di Paud Baitunnur Gentan Sleman menunjukkan bahwa pengetahuan guru dan wali murid Paud Baitunnur tentang SDIDTK meningkat dari rerata skor 62,5 menjadi 81,39.Adanya peningkatan pengetahuan pada guru dan wali murid di Sekolah TK Aisyiyah Bustanul Athfal 12 Malang, diharapkan guru dan wali murid dapat melakukan program deteksi dini dan stimulasi tumbuh kembang pada anak usia prasekolah.

Berdasarkan Hasil Riskesda (2013) menunjukkan bahwa angka prevalensi stunting nasional mencapai 37,2\% untuk jumlah anak dengan kondisi stunting (Pulungan AB, 2016). Hal ini berarti masalah tumbuh kembang pada anak memerlukan perhatian yang serius terutama pada orang tua. Salah satu cara untuk mengatasi masalah tumbuh kembang pada anak melalui peran aktif orang tua dalam melakukan upaya pemantauan pertumbuhan dan perkembangan anak yang dinamakan Program Stimulasi Deteksi Intervensi Dini Tumbuh Kembang (SDIDTK).

Secara umum tindak lanjut dari kegiatan penelitian di TK Aisyiyah Bustanul Athfal
12 Malang setelah mengikuti kegiatan seminar sehari adalah membentuk kader deteksi dini tumbuh kembang baik dari orang tua wali siswa dan guru TK di dalam memantau pertumbuhan dan perkembangan siswa TK. Selain itu para orangtua walisiswa dan guru juga menjadi lebih "aware" akan adanya disfungsi tumbuh kembang yang ada di lingkungan sekitar mereka dan mampu memberi solusi dan saran atas temuan permasalahan tumbuh kembang anak yang dihadapi oleh masyarakat.

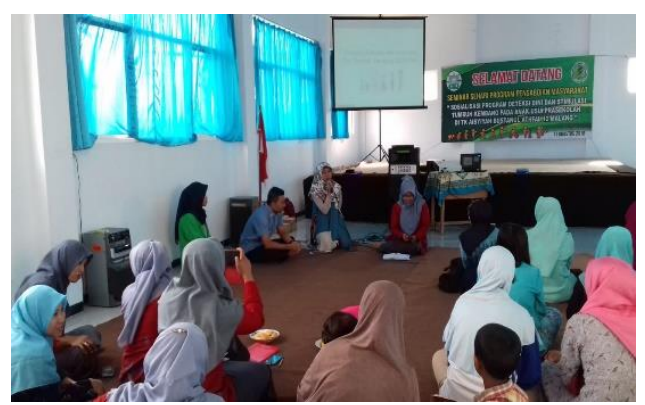

Gb.2 Kegiatan Psikoeduksi : Seminar

\section{KESIMPULAN}

1. Berdasarkan hasil pemeriksaan deteksi dini tumbuh kembang pada siswa TK Aisyiyah Bustanul Athfal 12, didapatkan bahwa ada beberapa siswa mengalami penyimpangan pada pemeriksaan KPSP sejumlah 4 siswa, 5 siswa mengalami gangguan pemusatan perhatian dan hiperaktivitas serta 1 siswa yang mengalami autis. 
2. Evaluasi hasil kegiatan psikoedukasi berupa seminar kepada orangtua dan guru TK, menunjukkan bahwa para peserta menyatakan bertambahnya pemahaman mereka mengenai karakteristik tumbuh kembang anak usia prasekolah dan bertambah pula keterampilan dalam mendeteksi secara dini disfungsi tumbuh kembang anak.

Direkomendasikan kepada orang tua wali siswa dan guru di Sekolah TK Aisyiyah Bustanul Athfal 12 Malang, diharapkan setelah kegiatan psikoedukasi berupa seminar ini guru dan orang tua wali siswa membentuk kelompok atau kader untuk melakukan upaya deteksi dini tumbuh kembang secara mandiri

\section{UCAPAN TERIMAKASIH}

Ucapan terima kasih diberikan kepada LPPMK Stikes Widyagama Husada selaku sumber dana penelitian dan pihak yang mendukung terlaksananya kegiatan penelitian.

\section{REFERENSI}

Depkes RI.(2007).Pedoman Pelaksanaan Stimuasi, Deteksi dan Intervensi Dini Tumbuh Kembang Anak di Tingkat Pelayanan Kesehatan Dasar. Jakarta.

Irmawati.(2007).Analisis Hubungan Fungsi Manajemen Pelaksana Kegiatan Stimulasi Deteksi dan Intervensi Dini Tumbub Kembang (SDIDTK) dengan Cakupan SDIDTK Balita dan Anak Pra Sekolah di Puskesmas Kota Semarang Tabun 2007 (Tesis). Undip Semarang. Semarang.

Kemenkes RI. (2012). Instrumen stimulasi, deteksi dan intervensi dini tumbub kembang anak. Jakarta

Kemenkes RI.(2013). Pedoman Pelaksanaan Stimulasi Deteksi dan Intervensi Dini Tumbuh Kembang Anak di Tingkat Pelayanan Kesehatan Dasar.Jakarta.

Keputusan Menteri kesehatan Republik Indonesia. (2010). Nomor 1995/Menkes/SK/XII/2010 tentang standar antropometri penilaian status gizi anak, Dirjen Bina Gizi dan Kesehatan Ibu dan Anak.Direktorat Bina Gizi.

Notoatmojo, S.(2012). Metode Penelitian Kesehatan . Rineka Cipta. Jakarta

Oberlander, J.R. Slow and Steady.(2003). Get Me Ready. Terjemahan oleh Soesanti Harini Hartono. Gramedia. Jakarta

Paparan RISKESDA (2013). Diunduh darihttp//:www.labdata.litbang.depk es.go.id

Pulungan AB (2016). Aplikasi Digital Untuk Pantau Tumbuh Kembang Anak. Makalah disampaikan pada PIT Bidan tanggal 3 November 2016 di Batam

Putri, RM., Maemunah,N., Rahayu,W. (2016). Pemeriksaan Pertumbuhan dan Personal Hyigiene Anak Pra Sekolah di RA Pesantren Al Madaniyah. JAPI Jurnal Akeses Pengabdian Indonesia) Vol 1(1) p.55-64 https://jurnal.unitri.ac.id/index.php /japi/article/view/459/478

Saidah, E.S.(2003). Pentingnya Stimulasi Mental Dini. Jurnal Ilmiah Pendidikan Anak Usia Dini. No.01.hlm. 50-55

Soccoro A Gultiano, Elizabeth M King.(2006). A Better Start in Life : Evaluation Results from an Early Childhood Development Program. Philippine Journal of Development. Vol.33,lss.1/2,pg.101, 28

Soetjiningsih.(1998). Tumbuh Kembang Anak. EGC. Jakarta 
Ummah F, Turlina L, Kusbiantoro D

(2016). IbM Optimasi Peran Guru PAUD untuk Meningkatkan Tumbub Kembang Anak Prasekolah. Makalah RAKERNAS AIPKEMA 2016

"Temu Ilmiah Hasil Penelitian dan Pengabdian Masyarakat

Widyastuti, D, dan Widyani, R. (2008). Panduan Perkembangan Anak 0 Sampai 1 Tahun. Jakarta: Puspa Swara

Yuliani, Istri. (2018). Pelatihan Stimulasi Deteksi Intervensi Dini Tumbuh
Kembang(SDIDTK) pada Paud Baitunnur Gentan Siduharjo Ngaglik Sleman. Jurnal Pengabdian" Dharma Bakti" Vol.1, No.1 